\title{
Evidências de validade psicométricas do Inventário de Estressores no Trabalho em Oncologia
}

\author{
Angela de Fátima Saraiva Freitas ${ }^{1, *}$, Luciana Mourão ${ }^{1}$
}

${ }^{1}$ Universidade Salgado de Oliveira (UNIVERSO), Brasil

Submissão: 06/01/2019

Primeira decisão editorial: 11/08/2019

Versão final: $02 / 11 / 2019$

Aceite: 05/11/2019

\section{Resumo}

O trabalho dos profissionais da saúde em oncologia é impactado por fatores estressores de diversas naturezas. O presente estudo objetivou realizar a adaptação do Inventário de Estressores no Trabalho em Oncologia para o Brasil e testar evidências de validade. O inventário foi aplicado a 384 profissionais, a maioria do sexo feminino e da Região Sudeste, com tempo médio de trabalho na oncologia de 9,4 anos. Foram realizadas análises fatoriais exploratória e confirmatória, e avaliação da confiabilidade e da invariância do instrumento entre enfermeiros e outras categorias ocupacionais. As análises confirmaram a quantidade de dimensões do modelo original, porém indicaram a redução da quantidade de itens, resultando em uma estrutura de cinco dimensões e 25 itens. Os resultados sugerem um instrumento com boas propriedades psicométricas, o que permite que seu uso seja recomendado em amostras brasileiras.

Palavras-chave: estressor ocupacional, psicometria, profissionais da saúde.

\section{Evidence of psychometric validity of the inventory of stressors in work in oncology}

\section{Evidencias de validez psicométricas del inventario de estresores en el trabajo en oncología}

\begin{abstract}
Stressors of various natures impact the work of oncology health professionals. The present study aimed to perform the adaptation to Brazil of the Inventory of Stressors in Oncology and to test evidences of its validity. The inventory was applied to 384 professionals, most of them females from the Southeast region, with a mean working time in oncology of 9.4 years. Exploratory and confirmatory factorial analysis, evaluation of scale reliability and invariance among nurses and other occupational categories were conducted. The analyzes confirmed the quantity of dimensions of the original model, but recommended the reduction of the quantity of items to a five-dimension structure and 25 items. The results suggest that this is an instrument with good psychometric properties, which endorse its use in Brazilian samples.
\end{abstract}

Keywords: occupational stressors, psychometry, health professionals.

\section{Resumen}

El trabajo de los profesionales de la salud en oncología es impactado por factores estresores de diversas naturalezas. El presente estudio objetivó fue realizar la adaptación para Brasil y probar evidencias de validez del Inventario de Estrés en el Trabajo en Oncología. El inventario fue aplicado a 384 profesionales, la mayoría del sexo femenino y de la región Sudeste, con tiempo medio de trabajo en la oncología de 9,4 años. Se realizaron análisis factoriales exploratorios y confirmatorios, evaluación de la confiabilidad y de la invariancia de la escala entre los enfermeros y otras categorías ocupacionales. Los análisis confirmaron la cantidad de dimensiones del modelo original, pero con reducción de la cantidad de ítems, resultando en una estructura de cinco dimensiones y 25 ítems. Los resultados sugieren un instrumento con buenas propiedades psicométricas, que permiten recomendar su uso en muestras brasileñas.

Palabras-clave: estresores ocupacionales; psicometría; profesionales de la salud. 
O estresse tem sido um fenômeno frequente em profissionais da saúde, deixando esses trabalhadores vulneráveis a alterações de ordens física, cognitiva ou emocional (Andela, Truchot, \& Van der Doef, 2016). Para Selye (1956), o estresse caracteriza-se como uma síndrome de adaptação ocasionada por um evento ambiental que exige esforço do indivíduo para se adaptar à situação, abalando a sua homeostase interna e alterando a constância de funcionamento do organismo. Pesquisas recentes têm considerado que os fatores que levam um indivíduo a vivenciar estresse podem ter não só origem externa (p. ex., perda de ente querido, mudanças no trabalho) como também origem interna (p. ex., doenças, emoções, gravidez) (Andolhe, Barbosa, Oliveira, Costa, \& Padilha, 2015). No mundo do trabalho, um expressivo conjunto de fatores estressores tem sido pesquisado, tais como: jornada e carga de trabalho excessivas, conflitos entre pessoas, liderança ineficiente, condições físicas precárias, exigências de desempenho acima da média, metas difíceis de alcançar, entre outros (Bandeira, 2017; Sousa \& Araújo, 2015).

De fato, o estresse no trabalho tem sido considerado um dos principais problemas da modernidade, capaz de provocar alterações no ritmo e na produtividade dos trabalhadores, ausências e afastamentos do serviço, por sintomas inespecíficos, por vezes confundidos com desinteresse, comodismo e preguiça (Sena, Lemes, Nascimento, \& Rocha, 2015). A preocupação com o estresse ocupacional na área da saúde e as suas consequências para a saúde do trabalhador são mais frequentes do que em outras áreas de trabalho (Sousa \& Araújo, 2015).

O trabalho na área apresenta características que contribuem para gerar estresse, na medida em que os profissionais lidam, diariamente, com situações que mobilizam suas emoções (Ribeiro, Marzlale, Martins, Galdino, \& Ribeiro, 2018). Nesse sentido, possíveis fatores estressores para os profissionais da saúde seriam: (i) o contato frequente com a dor, o sofrimento, a perspectiva de morte ou a própria morte; (ii) lidar com pacientes difíceis - rebeldes, agressivos, hostis, deprimidos, exigentes; (iii) lidar com as incertezas e as limitações do conhecimento científico para atender a todas as demandas dos pacientes; (iv) gerenciar problemas de relacionamento no âmbito da equipe de trabalho; (v) atuar em contexto de ambiguidade e conflito de funções; e (vi) trabalhar em dupla jornada (Andolhe et al., 2015; Balayssac et al., 2017; Ribeiro et al., 2018).

$\mathrm{Na}$ revisão da literatura realizada para embasar este estudo, detectou-se que a maioria dos estudos empíricos sobre estresse ocupacional na área da saúde concentra-se em uma ou duas profissões dessa área (Andolhe et al., 2015; Kitze \& Rodrigues, 2008). Ademais, estudos empíricos sobre estresse em profissões da área da saúde, que não enfermeiros e médicos, foram identificados em pequena quantidade na literatura brasileira, tais como: farmacêuticos (Balayssac et al., 2017); técnicos de laboratório (Sousa \& Araújo, 2015); psicólogos (Sanzovo \& Coelho, 2007); psicólogos e assistentes sociais (Maturana \& Valle, 2014); e fisioterapeutas, fonoaudiólogos e terapeutas ocupacionais (Bruschini, Carli, \& Franco, 2018). Na comparação entre os resultados dos estudos feitos com essas categorias ocupacionais e os estudos feitos com médicos e enfermeiros, juntos ou isoladamente (Bandeira \& Oliveira, 2010; Bandeira, 2017; Ratochinski, Powlowytsch, Grzelczak, Souza, \& Mascarenhas, 2016), percebe-se que a maioria dos fatores estressores apontados nos resultados é comum a diversas profissões da área da saúde.

No que tange especificamente à área da oncologia, uma revisão de literatura com 33 estudos sobre situações da área oncológica que provocam sofrimento psicológico nos profissionais da saúde mostrou que esses trabalhadores apresentam maior risco de estresse laboral (L. C. Silva, 2009). Entre as diversas situações geradoras de sofrimento no trabalhador da oncologia, três merecem destaque pela semelhança entre estudos nacionais e estrangeiros: envolvimento emocional com o paciente e seus familiares gerado pelo longo tratamento; expressões psicológicas de desamparo, medo e desespero no cotidiano profissional; e impotência diante da doença e da morte (Borteyrou, Truchot, \& Rascle, 2013; Onan et al., 2015; N. A. R. Santos, Santos, Silva, \& Passos, 2017; Silva, 2009). Merece atenção o fato de a maioria dos estudos empíricos sobre o estresse ocupacional com profissionais da área da saúde oncológica ser realizado exclusivamente com enfermeiros.

Ademais, verificou-se que a maior parte dos estudos empíricos sobre estresse, brasileiros e estrangeiros, utiliza escalas não construídas e validadas especificamente para a área da saúde, como, por exemplo, o Inventário de Sintomas de Stress para Adultos (ISSL) (Lipp, 2000); a Job Stress Scale (JSS) (Alves, Chor, Faerstein, Lopes, \& Werneck, 2004); e a Escala de Estresse no Trabalho (EET) (Paschoal \& Tamayo, 2004). Desse modo, não mensuram fatores estressores peculiares aos ambientes da área da saúde.

Realizou-se, então, uma busca nas bases de dados SciELO, PePSI e BVS por medidas específicas para o estresse na área da saúde. Considerando o período de 2007 a 2017 e usando os descritores "medida", "inventário", "escala", "estresse”, "saúde” e “oncologia", foram identificados seis instrumentos, apontados na Tabela 1, para identificação do estresse. Destas, apenas a de Borteyrou et al. (2013) volta-se especificamente para a área da saúde em oncologia.

Diante desse cenário, a escolha para este estudo recaiu sobre o Inventário de Estressores no Trabalho para Enfermeiros em Oncologia, desenvolvido por Borteyrou et al. (2013), por ser o único que aborda itens e dimensões especificamente construídos para a área oncológica. Além disso, a versão original da medida apresenta bons indicadores psicométricos, pois as cargas fatoriais dos 50 itens variaram de 0,39 a 0,89, com média de 0,61. O grau de confiabilidade das cinco dimensões, medido pelo alfa de Cronbach, foi bastante satisfatório, variando de 0,83 a 0,92 (média de 0,86).

Assim, optou-se pelo uso da adaptação cultural dessa medida e da testagem de seu uso em outras categorias da área da oncologia além da enfermagem. A decisão de ampliar o público-alvo do instrumento baseou-se no fato de os profissionais da área oncológica vivenciarem situações similares no trabalho, em virtude da multiprofissionalidade que caracteriza a área (Oliveira \& Cury, 2016; A. F. Santos \& Santos, 2015; L. C. Silva, 2009). Nesse sentido, o inventário poderá ser utilizado para medir o grau de estresse em diversas categorias ocupacionais da oncologia, permitindo a comparação de possíveis fatores estressores nas diferentes especialidades.

Assim, este estudo tem como objetivo realizar a adaptação do Inventário de Estressores no Trabalho em Oncologia, desenvolvido por Borteyrou et al. (2013), para o Brasil, bem como realizar os testes iniciais de validade psicométrica. Além disso, objetiva-se também estender essa medida para outros profissionais da saúde que atuam na área da oncologia, considerando que o estresse também pode acometer esses outros trabalhadores e não somente os enfermeiros.

Quanto à compatibilidade do Inventário de Estressores no Trabalho em Oncologia com outras categorias profissionais da saúde além da enfermagem, é preciso fazer uma comparação das dimensões do instrumento com os estressores indicados pela literatura da área para profissionais de diferentes categorias. Nesse sentido, é apresentado, a seguir, um paralelo entre os resultados da literatura da área e as características do inventário desenvolvido por Borteyrou et al. (2013).

A metanálise realizada por Bandeira e Oliveira (2010) a partir da base de dados da Scientific Electronic Library Online (SciELO), do período de 1998 a 2009, identificou 10 estudos sobre fatores estressores no trabalho da enfermagem. Sobre o mesmo assunto, Ratochinski et al. (2016) realizaram uma revisão sistemática de literatura, do período de 2000 a 2012, utilizan- 
Tabela 1

Instrumentos de mensuração de estresse em profissionais da saúde

\begin{tabular}{|c|c|c|}
\hline Instrumento/autor & $\begin{array}{l}\text { População } \\
\text { pesquisada }\end{array}$ & Dimensões/itens \\
\hline $\begin{array}{l}\text { The Nursing Stress } \\
\text { Scale } \\
\text { (Escala de Estresse } \\
\text { em Enfermagem) } \\
\text { (Gray-Toft \& Ander- } \\
\text { son, 1981) }\end{array}$ & $\begin{array}{l}\text { Enfermeiros, } \\
\text { técnicos de } \\
\text { enfermagem } \\
\text { de hospitais } \\
\text { de medicina } \\
\text { geral, cirurgia, } \\
\text { cirurgia } \\
\text { cardiovascular, } \\
\text { oncologia e } \\
\text { hospício. }\end{array}$ & $\begin{array}{c}\text { Sete dimensões (34 itens): } \\
\text { morte e morrer; conflito } \\
\text { com médicos; preparação } \\
\text { inadequada para lidar com as } \\
\text { necessidades emocionais dos } \\
\text { pacientes e suas famílias; falta } \\
\text { de apoio dos colegas; conflito } \\
\text { com outros enfermeiros e } \\
\text { supervisores; incerteza em } \\
\text { relação ao tratamento }\end{array}$ \\
\hline $\begin{array}{l}\text { The Health Professions } \\
\text { Stress Inventory (In- } \\
\text { ventário de Estresse } \\
\text { das Profissões da } \\
\text { Saúde) } \\
\text { (Wolfgang, 1988) }\end{array}$ & $\begin{array}{l}\text { Médicos, far- } \\
\text { macêuticos e } \\
\text { enfermeiros. }\end{array}$ & $\begin{array}{l}\text { Unifatorial (30 itens): com } \\
\text { análises separadas e cálculo de } \\
\text { confiabilidade para médicos, } \\
\text { farmacêuticos e enfermeiros. }\end{array}$ \\
\hline $\begin{array}{c}\text { Work-Related Strain } \\
\text { Inventory } \\
\text { (Inventário de Stress } \\
\text { Relacionado ao } \\
\text { Trabalho) } \\
\text { (Revicki et al., 1991) }\end{array}$ & $\begin{array}{l}\text { Médicos de fa- } \\
\text { mília, técnicos } \\
\text { de emergên- } \\
\text { cia médica, } \\
\text { enfermeiros } \\
\text { hospitalares, } \\
\text { enfermeiros } \\
\text { de voo e } \\
\text { residentes de } \\
\text { medicina. }\end{array}$ & Unifatorial (18 itens). \\
\hline
\end{tabular}

Seis dimensões (51 itens): relacionamento com unidades e supervisores; atividades para funcionamento adequado da

Bianchi Stress Scale (Escala Bianchi de Stress) (Bianchi, 2009)

Enfermeiros. unidade; atividades de administração de pessoal; assistência ao paciente; coordenação de atividades; condições de trabalho.

Oito fatores (22 itens): má comunicação no trabalho; falta de apoio de enfermeiros seniores; pessoal inadequado para desempenhar funções; relacionamento ruim; muita interrupção durante as tarefas; baixo nível de valores compartilhados pela equipe; falta de apoio da administração; mudanças nas férias planejadas e folgas.

Work Stressor Inventory for Nurses in Oncology (Inventário de Estressores do Trabalho para Enfermeiros em Oncologia)

(Borteyrou et al., 2013) brecarga de trabalho; jornada de trabalho exaustiva; dupla jornada de trabalho; relacionamento com o paciente; conflitos com outros profissionais; óbito dos pacientes; e estrutura organizacional.

Bandeira (2017) apresentou uma revisão de literatura sobre o estresse ocupacional na profissão do médico, com publicações no período de 2002 a 2014 nas bases de dados SciELO, Periódicos Eletrônicos de Psicologia (PePSIC), Medical Literature Analysis and Retrieval System Online (MEDLINE) e LILACS. O autor concluiu que a profissão de médico está fortemente associada ao estresse ocupacional e apontou fatores estressores específicos na profissão, tais como: diversos empregos; carga horária exaustiva; dificuldade para tirar férias; mais horas de trabalho do que outras profissões da saúde; constantes especializações; conflitos com superiores; comunicação do diagnóstico a pacientes e familiares; e dificuldade de cuidar das necessidades emocionais dos pacientes.

A escala original de Borteyrou et al. (2013) conta com cinco fatores, agrupados nas categorias cuidados diretos e não diretos de atenção ao paciente. Na categoria de cuidados não diretos ao paciente, há dois fatores. O primeiro refere-se à "carga de trabalho" (p. ex., "trabalho excessivo"), contemplando 19 itens, com alfa de Cronbach de 0,92 e cargas fatoriais de 0,45 a 0,77 . O segundo fator, "estresse com colegas de trabalho", tem oito itens e refere-se a relacionamentos conflituosos com pessoas da equipe (p. ex., "lidar com colegas desagradáveis"). O grau de confiabilidade dessa dimensão (medido pelo Alfa de Cronbach) foi de 0,83 , e as cargas fatoriais variaram de 0,50 a 0,65.

$\mathrm{Na}$ categoria de cuidados diretos ao paciente, há três fatores. O primeiro fator, "morte e processo da morte", está relacionado, sobretudo, à morte de pacientes jovens ou a uma convivência prolongada com o paciente (p. ex. "morte de pacientes jovens, de mães jovens ou de crianças”). Esse fator contempla 11 itens, com alfa de Cronbach de 0,83 e cargas fatoriais de 0,39 a 0,67. O segundo fator é "sofrimento do paciente", contemplando a dor e a falta de eficácia do tratamento que expõem os profissionais à frustração ou desamparo (p. ex., "ausência de esperança terapêutica"). Tal fator compreende sete itens, com alfa de Cronbach de 0,87 e cargas fatoriais entre 0,45 e 0,89 . Por fim, o fator "lidar com requisitos dos pacientes e familiares" contempla uma dimensão que é frequentemente estudada na oncologia (p. ex., "falta de cooperação de familiares com o paciente"). Esse último fator tem cinco itens, com alfa de Cronbach de 0,85 e cargas de 0,44 a 0,89.

A análise do inventário de Borteyrou et al. (2013) indicou, portanto, que, do ponto de vista teórico, a medida consegue contemplar os principais estressores laborais relativos a diferentes categorias ocupacionais da área oncológica. Diante dessa análise, foi delineado um método que permitisse realizar os testes iniciais de validade psicométrica do Inventário de Estressores no Trabalho em Oncologia considerando outros profissionais ocupacionais que atuam na área além dos enfermeiros. Assim, o método descrito a seguir contemplou a análise de invariância da medida para outras categorias profissionais da área da oncologia, para testar se, além de pertinência teórica, há também pertinência psicométrica para ampliar o uso deste inventário para outras categorias ocupacionais.

\section{Método}

\section{Participantes}

A versão do Inventário de Estressores no Trabalho em Oncologia adaptada para a realidade brasileira foi aplicada a uma amostra de conveniência de 385 participantes, tendo sido excluído apenas um participante no processo de limpeza do banco de dados, de forma a atender às recomendações de número mínimo de cinco participantes por item do instrumento (Hair, Black, Babin, estro estresse, os autores apontam, entre outros: recursos e condições inadequadas para o desempenho da atividade; carga horária; so- 
Anderson, \& Tathan, 2009). Considerando o objetivo de expandir a medida de Borteyrou et al. (2013) para outros profissionais que atuam na área oncológica, estabeleceu-se como condição de entrada para a pesquisa o trabalho em alguma instituição de saúde com assistência a pacientes oncológicos, como assistente social, enfermeiro, fisioterapeuta, médico, nutricionista ou psicólogo. Como resultado, a amostra obtida contou com 41,7\% de enfermeiros e 58,3\% de pertencentes às demais categorias profissionais pesquisadas. Essa distribuição de enfermeiros e não enfermeiros decorreu da necessidade de realizar análise de invariância da medida para enfermeiros e para outras categorias ocupacionais da saúde oncológica, uma vez que o instrumento originalmente foi desenvolvido para os enfermeiros que atuam nessa área.

$\mathrm{Na}$ amostra, predominaram mulheres $(84,6 \%)$, pessoas casadas/união estável (59,4\%), residentes na Região Sudeste $(85,9 \%)$, com pós-graduação $(91,1 \%)$ e vínculo laboral exclusivamente com o setor público $(48,2 \%)$. A média do tempo de trabalho na área da oncologia foi de 9,4 anos ( $D P=7,6)$, e a carga semanal de trabalho de 41,6 horas $(D P=11,9)$. O detalhamento dos dados sociodemográficos da amostra é apresentado na Tabela 2, com a divisão dos dados relativos aos enfermeiros e aos demais profissionais da saúde.

$\mathrm{Na}$ Tabela 2, também são apresentados os resultados dos testes $\underline{t}$, para comparação das médias de caracterização da amostra desses dois públicos. Os resultados obtidos indicam que não há diferenças significativas entre as médias das diferentes variáveis que caracterizam as amostras de enfermeiros e as de outros profissionais que atuam na área da oncologia. Tabela 2

Dados sociodemográficos dos participantes $(N=384)$ e comparação das amostras de enfermeiros e outros profissionais da saúde da área oncológica

\begin{tabular}{|c|c|c|c|c|c|c|c|}
\hline \multirow{2}{*}{$\begin{array}{c}\text { Variável } \\
\text { Categoria profissional }\end{array}$} & \multicolumn{2}{|c|}{$\begin{array}{c}\text { Grupo } 1 \\
\text { Frequência } \\
(\%)\end{array}$} & \multicolumn{2}{|c|}{$\begin{array}{c}\text { Grupo } 2 \\
\text { Frequência } \\
(\%)\end{array}$} & \multicolumn{2}{|c|}{$\begin{array}{l}\text { Amostra } \\
\text { total } \\
\text { Frequência } \\
\quad(\%)\end{array}$} & \multirow[t]{2}{*}{$\begin{array}{l}\chi^{2} \\
\text { (qui- } \\
\text {-qua- } \\
\text { drado) }\end{array}$} \\
\hline & 160 & $(41,7)$ & 224 & $(58,3)$ & 384 & $(100,0)$ & \\
\hline \multicolumn{8}{|l|}{ Sexo } \\
\hline Feminino & 139 & $(86,9)$ & 186 & $(83,0)$ & 325 & $(84,6)$ & $\begin{array}{l}p= \\
0,30\end{array}$ \\
\hline \multicolumn{8}{|l|}{ Estado civil } \\
\hline Solteiro & 58 & $(36,3)$ & 68 & $(30,4)$ & 126 & $(32,8)$ & \multirow{5}{*}{$\begin{array}{c}\chi^{2(4)} \\
=4,42 \\
p= \\
0,35\end{array}$} \\
\hline Casado & 68 & $(42,5)$ & 106 & $(47,3)$ & 174 & $(45,3)$ & \\
\hline União estável & 25 & $(15,6)$ & 29 & $(12,9)$ & 54 & $(14,1)$ & \\
\hline Divorciado & 9 & $(5,6)$ & 19 & $(8,5)$ & 28 & $(7,3)$ & \\
\hline Viúvo & 0 & $(0,0)$ & 2 & $(0,9)$ & 2 & $(0,5)$ & \\
\hline \multicolumn{8}{|l|}{ Escolaridade } \\
\hline Graduação & 17 & $(10,6)$ & 17 & $(7,6)$ & 34 & $(8,9)$ & \multirow{3}{*}{$\begin{array}{c}\chi 2(2) \\
= \\
24,86 \\
p< \\
0,01\end{array}$} \\
\hline $\begin{array}{l}\text { Pós-graduação } \\
\text { Lato sensu }\end{array}$ & 112 & $(70,0)$ & 109 & $(48,7)$ & 221 & $(57,6)$ & \\
\hline $\begin{array}{l}\text { Pós-graduação } \\
\text { Stricto sensu }\end{array}$ & 31 & $(19,4)$ & 98 & $(43,7)$ & 129 & $(33,6)$ & \\
\hline \multicolumn{8}{|l|}{ Setor de trabalho } \\
\hline Público & 80 & $(50,0)$ & 105 & $(47,0)$ & 185 & $(48,2)$ & \multirow[b]{2}{*}{$\begin{array}{c}\chi^{2(3)} \\
=\end{array}$} \\
\hline Privado & 60 & $(37,5)$ & 48 & $(21,4)$ & 108 & $(28,1)$ & \\
\hline Filantrópico & 10 & $(6,3)$ & 16 & $(7,1)$ & 26 & $(6,8)$ & \multirow{3}{*}{$\begin{array}{c}27,75 \\
p< \\
0,01\end{array}$} \\
\hline Misto & 7 & $(4,4)$ & 48 & $(21,4)$ & 55 & $(14,3)$ & \\
\hline Não informou & 3 & $(1,8)$ & 7 & $(3,1)$ & 10 & $(2,6)$ & \\
\hline \multicolumn{8}{|l|}{ Regiões do Brasil } \\
\hline Norte & 0 & $(0,0)$ & 8 & $(4,0)$ & 8 & $(2,3)$ & \multirow{6}{*}{$\begin{array}{c}\chi 2(4) \\
= \\
14,08 \\
p< \\
0,01\end{array}$} \\
\hline Nordeste & 1 & $(0,6)$ & 14 & $(6,3)$ & 15 & $(3,9)$ & \\
\hline Centro-oeste & 4 & $(2,5)$ & 7 & $(2,7)$ & 11 & $(2,6)$ & \\
\hline Sudeste & 144 & $(90,0)$ & 186 & $(83,0)$ & 330 & $(85,9)$ & \\
\hline Sul & 10 & $(6,3)$ & 9 & $(4,0)$ & 19 & $(4,9)$ & \\
\hline Não informou & 1 & $(0,6)$ & 0 & $(0,0)$ & 1 & $(0,3)$ & \\
\hline
\end{tabular}

Tabela 2 (continuação)

Dados sociodemográficos dos participantes $(N=384)$ e comparação das amostras de enfermeiros e outros profissionais da saúde da área oncológica

\begin{tabular}{|c|c|c|c|c|c|c|}
\hline Variável & \multicolumn{2}{|c|}{$\begin{array}{c}\text { Grupo } 1 \\
\text { Média (DP) }\end{array}$} & \multicolumn{2}{|c|}{$\begin{array}{c}\text { Grupo } 2 \\
\text { Média }(D P)\end{array}$} & \multirow{2}{*}{$\begin{array}{c}\text { Amostra } \\
\text { total } \\
\text { Média } \\
(D P)\end{array}$} & \multirow{2}{*}{$\begin{array}{c}\text { Teste } t(g l) \\
t=1,15(382) \\
p=0,25\end{array}$} \\
\hline Idade & 37,4 & $(8,4)$ & 38,5 & $(9,7)$ & & \\
\hline $\begin{array}{l}\text { Tempo de traba- } \\
\text { lho (anos) }\end{array}$ & 13,8 & $(8,4)$ & 14,6 & $(9,3)$ & $\begin{array}{l}14,3 \\
(8,9)\end{array}$ & $t=1,47(381)$ \\
\hline $\begin{array}{l}\text { Tempo de traba- } \\
\text { lho na categoria } \\
\text { (anos) }\end{array}$ & 11,4 & $(8,2)$ & 12,7 & $(8,9)$ & $\begin{array}{l}12,1 \\
(8,6)\end{array}$ & $\begin{array}{c}t=-0,44 \\
(377) \\
p=0,66\end{array}$ \\
\hline $\begin{array}{l}\text { Tempo de traba- } \\
\text { lho em oncologia } \\
\text { (anos) }\end{array}$ & 9,61 & $(7,6)$ & 9,3 & $(7,7)$ & $9,4(7,6)$ & $\begin{array}{c}t=-0,44 \\
(377) \\
p=0,66\end{array}$ \\
\hline $\begin{array}{l}\text { Número de espe- } \\
\text { cializações }\end{array}$ & 1,7 & 1,1 & 1,9 & $(1,2)$ & $1,8(1,1)$ & $\begin{array}{c}t=1,33(382) \\
p=0,18\end{array}$ \\
\hline $\begin{array}{l}\text { Carga horária } \\
\text { semanal }\end{array}$ & 41,6 & $(9,2)$ & 41,5 & $(13,6)$ & $\begin{array}{c}41,6 \\
(11,9)\end{array}$ & $\begin{array}{c}t=-0,78 \\
(377) \\
p=0,94\end{array}$ \\
\hline $\begin{array}{l}\text { Quantidade de } \\
\text { empregos }\end{array}$ & 1,2 & $(0,6)$ & 1,4 & $(0,4)$ & $1,3(0,6)$ & $\begin{array}{c}t=5,9(345) \\
p<0,001\end{array}$ \\
\hline
\end{tabular}

Nota. Grupo 1 = enfermeiros; Grupo 2 = outros profissionais: assistente social, fisioterapeuta, médico, nutricionista e psicólogo; $D P=$ desvio-padrão; $g l=$ grau de liberdade; $\chi^{2}$ = qui-quadrado.

\section{Instrumento}

O instrumento de coleta de dados utilizado foi o Inventário de Estressores no Trabalho em Oncologia, desenvolvido por Borteyrou et al. (2013), cuja versão original foi desenvolvida com base em critérios qualitativos e quantitativos. Inicialmente, os autores realizaram entrevistas semiestruturadas com uma amostra de conveniência de 59 enfermeiras de seis unidades de oncologia na França, a fim de identificar os principais estressores laborais. Com base nesse estudo qualitativo, os autores construíram uma primeira versão do instrumento com 51 itens, distribuídos em oito fatores: carga de trabalho; estresse organizacional; estressores ambientais; conflitos de papéis; tratamento de pacientes e famílias; relações com colegas; tratamento de pacientes que sofrem e estão morrendo; e equilíbrio entre trabalho e vida. Essa primeira versão do instrumento foi aplicada em uma amostra de 582 enfermeiros da área da oncologia de hospitais gerais e oncológicos da França.

Os resultados da análise fatorial exploratória (AFE) da adaptação da escala para a versão brasileira apontaram para um inventário composto por 50 itens, agrupados em cinco dimensões. Os itens são respondidos em escala tipo Likert, variando de um (nunca) a cinco (diariamente), referindo-se à frequência com que o item ocorre no ambiente de trabalho.

Antes da sua aplicação, o instrumento passou por procedimentos de adaptação e testes iniciais de validade psicométrica entre culturas recomendado por Borsa, Damásio e Bandeira (2012). A primeira etapa foi a tradução do instrumento, feita individualmente por dois tradutores bilíngues, do inglês para o português, sendo um deles familiarizado com o construto avaliado. Pelo fato de as duas traduções terem ficado similares, foi elaborada, em seguida, a versão brasileira do instrumento, submetida à avaliação individual de oito especialistas da oncologia com domínio da língua inglesa, que concluíram que a tradução estava adequada. Após essa avaliação, a versão final em português foi submetida ao processo de retradução por um terceiro tradutor bilíngue familiarizado com o construto, mas que não tinha conhecimento das traduções anteriores.

Por fim, com a confirmação de que a tradução estava adequada, o instrumento foi submetido à validação semântica em um 
grupo de 15 profissionais da área oncológica, selecionados pelo critério de conveniência e disponibilidade de tempo para realizar a tarefa. Participaram desse processo quatro assistentes sociais, duas enfermeiras, uma fisioterapeuta, uma médica, cinco nutricionistas e duas psicólogas, todas do sexo feminino, com idade média de 41,5 anos $(D P=9,06)$, tempo médio de trabalho na área da oncologia de 11,5 anos $(D P=8,7)$. Nessa etapa, não houve indicação de alteração no instrumento.

\section{Procedimentos de Coleta de Dados e Cuidados Éticos}

Após a validação semântica do instrumento e a aprovação da pesquisa pelo Comitê de Ética em Pesquisa com Seres Humanos da Universidade Salgado de Oliveira (Universo) (CAEE 89856218.4.000.5289), o inventário foi disponibilizado para a coleta de dados, tanto por meio eletrônico, com o apoio de uma ferramenta on-line (Google Docs), quanto por meio de questionário em papel. Em sua parte inicial, foram informados os objetivos da pesquisa, a garantia de anonimato e a condição para participação (trabalhar como assistente social, enfermeiro, médico, nutricionista, fisioterapeuta ou psicólogo em instituição de saúde com atendimento a pacientes oncológicos). O respondente deveria concordar com as condições do Termo de Consentimento Livre e Esclarecido (TCLE).

A busca inicial de participantes ocorreu por meio de contato direto e entrega do questionário de pesquisa impresso aos profissionais nas instituições de saúde que atendem a pacientes oncológicos. Tal abordagem teve uma taxa de retorno muito baixa $(10 \%)$ - dos mais de 800 questionários entregues, apenas 78 foram respondidos. Em paralelo, usando a Plataforma Lattes e duas redes sociais (Facebook e LinkedIn), foi enviado o convite para responder ao questionário on-line. De 4.500 solicitações de conexão nas redes sociais, 2.000 foram aceitas, obtendo-se 306 questionários respondidos $(15,3 \%$ de taxa de retorno). A coleta durou de maio a setembro de 2018. Essa taxa de retorno foi baixa, mas acima de patamares em geral frequentes para pesquisas pela internet realizadas com profissionais da saúde (Apostolico \& Egry, 2013; A. M. Silva, Rodrigues, Silva, \& Witt, 2009).

\section{Procedimentos de Análise de Dados}

Para verificação das propriedades psicométricas do inventário, os dados coletados foram analisados com o apoio dos softwares IBM SPSS Statistics e o IBM SPSS AMOS, ambos com versão 21.0. $\mathrm{Na}$ limpeza do banco de dados, foi excluído apenas um questionário, que tinha $25 \%$ das respostas em branco, ultrapassando o patamar de 10\% sugerido por Hair et al. (2009) como limite máximo aceitável. Foram feitas AFE e análise fatorial confirmatória (AFC) para avaliar a validade do instrumento. Embora, idealmente, devam ser utilizadas amostras distintas para essas duas análises, o tamanho amostral obtido na pesquisa e o número de itens do instrumento não permitiram realizar as análises com duas amostras independentes.

A análise iniciou com a realização do teste de esfericidade de Bartlett e do índice Kaiser-Meyer-Olkin (KMO), sendo os parâmetros adotados, respectivamente, ser significativo e ter valores acima de 0,70 (Hair et al., 2009). Na AFE, foram utilizados o método de análise da fatoração de eixo principal (PAF) e o método de rotação oblíquo. Para definição do número de fatores, foram adotados os critérios da análise paralela, conforme a recomendação de Damásio (2012) de comparar os autovalores empíricos com as médias dos autovalores randômicos oriundas da matriz hipotética fatorada a partir de simulação Monte-Carlo. A definição do número de fatores a serem retidos referiu-se àqueles que apresentassem, simultaneamente, autovalor empírico $>1$ e supe- rior ao respectivo autovalor obtido por meio dos dados aleatórios. Adicionalmente, foi avaliada a consistência teórica dos itens, além do critério mínimo de três itens por dimensão, sendo cada um com cargas fatoriais iguais ou superiores a 0,32 (Hair et al., 2009). Nos casos de itens que carregaram em dois fatores, foram mantidos somente aqueles cuja diferença entre as cargas fatoriais fosse superior a 0,30 , sendo a permanência do item no fator em que ele tivesse, simultaneamente, maior carga fatorial e adequação teórica.

Foi também realizada correlação de Pearson entre as dimensões resultantes da análise fatorial. O parâmetro adotado para a análise de magnitude foi o de Miles e Shevlin (2001), que consideram intensidade moderada entre 0,30 e 0,49 e intensidade elevada para valores superiores a 0,50. Para a estimativa da confiabilidade do instrumento foram calculados os alfas de Cronbach, sendo desejáveis valores iguais ou superiores a 0,70.

$\mathrm{Na} \mathrm{AFC}$, como os dados apresentavam normalidade multivariada, foi utilizado o método de estimação Maximuum Likelihood. A análise de adequação do modelo considerou como índices de ajustamento: razão crítica entre o qui-quadrado e os graus de liberdade $<$ 5,0; Tucker-Lewis Index (TLI) > 0,90; e Comparative Fit Index (CFI) $>0,90$. Como índice de parcimônia do modelo, foi utilizado o Root Mean Square Error of Approximation (RMSEA) <0,05 (Brown, 2006).

Também foi realizada uma análise de invariância comparando a medida para enfermeiros e demais categorias ocupacionais da área da saúde, por meio da técnica de análise fatorial confirmatória multigrupo (AFCMG), que se propõe a avaliar em que medida a configuração e os parâmetros de um instrumento podem ser equivalentes para grupos diferentes (Damásio, 2013). A razão para tal comparação deve-se ao fato de que a medida original foi construída especificamente para enfermeiros que atuam na área oncológica. Foram avaliadas as invariâncias configural, métrica, escalar e residual. Para tanto, foram analisados os aumentos no CFI, com valores inferiores a 0,01 sendo considerados invariantes (Damásio, 2013).

\section{Resultados}

\section{Análise Fatorial Exploratória}

Os resultados obtidos nas análises iniciais revelaram que os dados atendiam aos pressupostos da análise fatorial, com KMO de 0,90 e teste de esfericidade de Bartlet significativo $\left(\chi^{2}\right.$ $=11.161,48 ; \mathrm{p}<0,001)$. O número de fatores do instrumento foi definido a partir dos resultados da análise paralela, que indicou, inicialmente, a existência de até seis dimensões cujos autovalores empíricos eram superiores aos autovalores randômicos (Damásio, 2012). Foi feita, então, uma análise inicial com possíveis seis dimensões que mostrou pouca consistência teórica com fatores não claramente definidos e muitos itens carregando em mais de um fator. Uma nova análise de estrutura fatorial com cinco dimensões foi testada e apresentou-se mais adequada.

Nessa distribuição de cinco dimensões, nove itens não apresentaram bom ajuste, sendo um expressivo número (sete itens) da dimensão "carga de trabalho", além de dois itens da dimensão "lidar com a morte e o processo da morte". Desse modo, foi realizada uma nova AFE com a manutenção de cinco fatores, tais como previstos na versão francesa da medida, e com 41 itens em função da redução mencionada. Essa solução apontou para um item da dimensão "lidar com a morte e processo da morte" que não obteve carga fatorial suficiente $(\geq 0,32)$ em nenhum fator e dois outros itens dessa mesma dimensão que carregaram na dimensão "sofrimento dos pacientes", sendo, assim, excluídos das análises.

Nova AFE foi realizada com 38 itens, a qual apontou para a exclusão de dois itens que ficaram com cargas fatoriais abaixo de 0,32 , sendo um da dimensão "sofrimento dos pacientes" 
e outro da dimensão "estresse com colegas de trabalho". Em decorrência, os itens foram suprimidos do instrumento, e outra AFE foi realizada com 36 itens. O resultado alcançado com essa nova estrutura mostrou que os itens carregaram adequadamente em seus fatores respectivos, apresentando cargas fatoriais variando de 0,45 a 0,89 e com as cinco dimensões explicando $57,7 \%$ da variância das respostas aos itens. Assim, a estrutura fatorial resultante da AFE foi de uma escala com 36 itens e cinco dimensões.

A análise de compatibilidade teórica dos itens mostrou que as cinco dimensões têm sentido teórico. Além disso, o cálculo do alfa de Cronbach indicou elevado grau de confiabilidade para todas as dimensões. $\mathrm{O}$ número de itens em cada dimensão variou de cinco a 12, com os seguintes distribuição, graus de confiabilidade e cargas fatoriais: carga de trabalho (12 itens; $\alpha=0,90$; cargas fatoriais de 0,45 a 0,86$)$; lidar com a morte e o processo da morte ( 6 itens; $\alpha=0,89$; cargas fatoriais de 0,52 a 0,85 ); sofrimento dos pacientes ( 8 itens; $\alpha=0,87$; cargas fatoriais de 0,49 a 0,89 ); estresse com colegas de trabalho ( 7 itens; $\alpha=0,85$; cargas fatoriais de 0,54 a 0,79$)$; e lidar com requisitos dos pacientes e familiares ( 5 itens; $\alpha=0,88$; cargas fatoriais de 0,59 a 0,88 ). Assim, a estrutura fatorial resultante da AFE foi de um inventário com 36 itens e cinco dimensões, apresentada na Tabela 3.

\section{Análise Fatorial Confirmatória}

Para avaliar a dimensionalidade do Inventário de Estressores no Trabalho em Oncologia, os dados foram analisados a partir da comparação entre modelos rivais por meio da modelagem por equações estruturais. Nesse sentido, testou-se o ajuste aos dados dos modelos fator geral, cinco dimensões não correlacionadas e cinco dimensões correlacionadas, conforme configuração da medida no estudo original de Borteyrou et al. (2013).

Para a AFC, seguiu-se inicialmente o critério estabelecido por Hair et al. (2009), de somente incluir itens com cargas fatoriais iguais ou superiores a 0,50 . Assim, foi retirado o item "ser constantemente interrompido" da dimensão "carga de trabalho", que apresentou carga fatorial de 0,45 na versão obtida na AFE (Tabela 3). Desse modo, foram inicialmente testados modelos rivais de estrutura latente com 35 itens. No primeiro modelo testado na AFC (Modelo 1 - Fator geral), os itens foram configurados para serem explicados por uma única dimensão. Esperava-se um modelo não ajustado aos dados, uma vez que uma dimensão geral indicaria ausência de validade discriminante entre as cinco dimensões latentes do Inventário de Estressores no Trabalho em Oncologia. Os indicadores apontaram para um modelo de dimensão geral com pobre ajuste aos dados, sinalizando, portanto, que os itens avaliam mais de uma dimensão latente.

O segundo modelo testado (Modelo 2 - Cinco dimensões não correlacionadas) seguiu a proposta de fatores do instrumento original de Borteyrou et al. (2013), que foi confirmada pela AFE na amostra com diferentes categorias ocupacionais que atuam na oncologia. Conforme pode ser visualizado na Tabela 4 , esse segundo modelo também não apresentou ajuste aos dados, indicando que as dimensões do Inventário de Estressores no Trabalho em Oncologia apresentam correlações entre si.

O modelo com 35 itens e cinco dimensões correlacionadas (Modelo 3 - Cinco dimensões - 35 itens) obteve melhor ajustamento do que os anteriores, confirmando a relação teórica hipotetizada. Apesar de se mostrar melhor do que os anteriores, o ajuste desse terceiro modelo não estava adequado, possivelmente pelo excessivo número de itens. Verificou-se, então, a configuração de cada dimensão que resultaria em um maior grau de confiabilidade. Assim, foram retirados dez itens, o que resultou na melhoria dos alfas de Cronbach, ficando cada uma das dimen-
Tabela 3

Estrutura fatorial do Inventário de Estressores no Trabalho em Oncologia resultante da AFE - versão adaptada para a realidade brasileira

\begin{tabular}{|c|c|c|c|}
\hline Fatores & & Itens & $\begin{array}{c}\text { Car- } \\
\text { ga } \\
\text { fato- } \\
\text { rial }\end{array}$ \\
\hline \multirow{12}{*}{$\begin{array}{l}\text { Fator 1: } \\
\text { Carga de } \\
\text { trabalho } \\
12 \text { itens } \\
\alpha=0,90\end{array}$} & 1 & Ser constantemente interrompido. & 0,45 \\
\hline & 2 & Trabalho excessivo. & 0,82 \\
\hline & 3 & Tempo insuficiente para realizar tarefas. & 0,75 \\
\hline & 4 & Ter muitos pacientes. & 0,63 \\
\hline & 5 & Estar envolvido com muitas tarefas diferentes. & 0,74 \\
\hline & 6 & Pessoal insuficiente na equipe de apoio. & 0,65 \\
\hline & 7 & Falta de tempo. & 0,86 \\
\hline & 8 & $\begin{array}{l}\text { Interrupções (telefone de emergência, } \\
\text { WhatsApp e outros). }\end{array}$ & 0,57 \\
\hline & 9 & Ter que trabalhar rapidamente. & 0,72 \\
\hline & 10 & Trabalho físico excessivo. & 0,63 \\
\hline & 11 & $\begin{array}{l}\text { Ter tanto trabalho que a qualidade fica prejudica- } \\
\text { da. }\end{array}$ & 0,65 \\
\hline & 12 & Tarefas administrativas em excesso. & 0,60 \\
\hline \multirow{6}{*}{$\begin{array}{l}\text { Fator 2: } \\
\text { Lidar com } \\
\text { a morte e o } \\
\text { processo da } \\
\text { morte } \\
6 \text { itens } \\
\alpha=0,89\end{array}$} & 13 & Cumulativos episódios de mortes. & $-0,77$ \\
\hline & 14 & Morte de pacientes de quem nos aproximamos. & $-0,69$ \\
\hline & 15 & Comunicar notícias ruins. & $-0,52$ \\
\hline & 16 & $\begin{array}{l}\text { Morte de pacientes jovens, de mães jovens ou } \\
\text { de crianças. }\end{array}$ & $-0,85$ \\
\hline & 17 & Presenciar momento da morte do paciente. & $-0,75$ \\
\hline & 18 & Pacientes jovens. & $-0,82$ \\
\hline \multirow{6}{*}{$\begin{array}{l}\text { Fator 3: } \\
\text { Sofrimento } \\
\text { dos pacientes } \\
6 \text { itens } \\
\alpha=0,87\end{array}$} & 19 & $\begin{array}{l}\text { Acompanhar a dor física e o sofrimento em } \\
\text { pacientes. }\end{array}$ & 0,78 \\
\hline & 20 & Perceber o sofrimento emocional dos pacientes. & 0,89 \\
\hline & 21 & Deterioração física dos pacientes. & 0,79 \\
\hline & 22 & Ausência de esperança terapêutica. & 0,49 \\
\hline & 23 & Preocupar-se com a solidão dos pacientes. & 0,67 \\
\hline & 24 & $\begin{array}{l}\text { Confrontar-se com a falta de aceitação da doen- } \\
\text { ça pelo paciente. }\end{array}$ & 0,58 \\
\hline \multirow{7}{*}{$\begin{array}{l}\text { Fator 4: } \\
\text { Estresse com } \\
\text { colegas de } \\
\text { trabalho } \\
7 \text { itens } \\
\alpha=0,85\end{array}$} & 25 & $\begin{array}{l}\text { Dificuldade de escuta por parte dos superiores } \\
\text { hierárquicos. }\end{array}$ & 0,61 \\
\hline & 26 & $\begin{array}{l}\text { Falta de reconhecimento pelo trabalho bem } \\
\text { feito. }\end{array}$ & 0,54 \\
\hline & 27 & Ter conflitos com colegas de trabalho. & 0,73 \\
\hline & 28 & $\begin{array}{l}\text { Estar em desacordo com o tratamento de um } \\
\text { paciente. }\end{array}$ & 0,58 \\
\hline & 29 & Lidar com colegas desagradáveis. & 0,79 \\
\hline & 30 & $\begin{array}{l}\text { Estar em desacordo com as práticas dos médi- } \\
\text { cos. }\end{array}$ & 0,56 \\
\hline & 31 & $\begin{array}{l}\text { Comunicação deficiente entre colegas de } \\
\text { trabalho. }\end{array}$ & 0,75 \\
\hline \multirow{5}{*}{$\begin{array}{l}\text { Fator } 5 \text { : } \\
\text { Lidar com } \\
\text { requisitos } \\
\text { dos pacientes } \\
\text { e familiares } \\
5 \text { itens } \\
\alpha=0,88\end{array}$} & 32 & Lidar com pacientes difíceis/exigentes. & 0,87 \\
\hline & 33 & $\begin{array}{l}\text { Lidar com familiares de pacientes difíceis/ } \\
\text { exigentes. }\end{array}$ & 0,88 \\
\hline & 34 & $\begin{array}{l}\text { Lidar com pacientes e/ou familiares hostis ou } \\
\text { violentos. }\end{array}$ & 0,81 \\
\hline & 35 & $\begin{array}{l}\text { Falta de cooperação de familiares com o } \\
\text { paciente. }\end{array}$ & 0,82 \\
\hline & 36 & $\begin{array}{l}\text { Existência de conflitos entre pacientes e sua } \\
\text { família. }\end{array}$ & 0,59 \\
\hline
\end{tabular}

Nota. Itens que carregaram em mais de uma dimensão, porém com uma diferença superior a 0,30 , foram mantidos na dimensão em que a carga fatorial era mais elevada.

sões com a seguinte configuração: carga de trabalho - sete itens $(\alpha=0,90)$; lidar com a morte e processo da morte - cinco itens $(\alpha=0,90)$; sofrimento dos pacientes - quatro itens $(\alpha=0,84)$; estresse com colegas de trabalho - cinco itens $(\alpha=0,84)$; e lidar com requisitos dos pacientes e familiares - quatro itens $(\alpha=$ 
0,89). O quarto modelo, com cinco dimensões correlacionadas e redução para 25 itens (Modelo 4 - Cinco dimensões - 25 itens), apresentou-se com valores de ajuste melhores que o Modelo 3.

Por fim, tendo em vista a análise do Modification Indices (MI), foi verificada uma elevada correlação entre três pares de itens, que resultariam em expressiva redução do qui-quadrado. Os itens correlacionados foram os seguintes: (i) "falta de cooperação de familiares com o paciente" e "lidar com pacientes e/ou familiares hostis ou violentos" ( $r=0,49, p<0,01$; MI = 89,70); (ii) "falta de reconhecimento pelo trabalho bem feito" e "dificuldade de escuta por parte dos superiores hierárquicos" ( $r=0,40$, $p<0,01 ; \mathrm{MI}=63,35)$; e (iii) "lidar com colegas desagradáveis" e "ter conflitos com colegas de trabalho" $(r=0,34, p<0,01$; MI $=20,97)$. Obteve-se, então, um modelo bem ajustado com cinco dimensões, 25 itens e razão crítica do qui-quadrado pelos graus de liberdade equivalente a 2,48. Além disso, os parâmetros TLI e CFI ficaram acima de 0,90 e com um modelo parcimonioso (RMSEA de 0,052 , com o intervalo de confiança de 0,90 variando de 0,056 a 0,068). Como resultado desse processo, considerou-se que o melhor modelo é o de cinco dimensões correlacionadas e com os ajustes indicados entre três pares de itens (Modelo 5 - Cinco dimensões - 25 itens ajustados). Embora esse modelo, assim como os demais, tenha apresentado um valor significativo para o qui-quadrado (que idealmente deveria ser não significativo), esse indicador não é um impeditivo para o modelo, tendo em vista que amostras grandes tendem a gerar qui-quadrados significativos (Hair et al., 2009) e que a razão do qui-quadrado pelos graus de liberdade ficou abaixo de 5,0 (Brown, 2006). A Tabela 4 apresenta os indicadores obtidos em cada um dos modelos testados.

Tabela 4

Indicadores obtidos nos modelos testados na análise fatorial confirmatória

\begin{tabular}{|c|c|c|c|c|c|c|}
\hline Modelos & $\chi^{2}$ & $g l$ & $\begin{array}{c}\chi^{2 /} \\
g l\end{array}$ & TLI & CFI & RMSEA \\
\hline $\begin{array}{c}\text { Modelo } 1 \\
\text { (Fator geral) }\end{array}$ & $5.002,3$ & 554 & 9,03 & 0,40 & 0,44 & 0,145 \\
\hline $\begin{array}{c}\text { Modelo } 2 \\
\text { (Cinco dimensões não } \\
\text { correlacionadas) }\end{array}$ & $2.358,3$ & 560 & 4,21 & 0,76 & 0,78 & 0,092 \\
\hline $\begin{array}{c}\text { Modelo } 3 \\
\text { (Cinco dimensões }-35 \\
\text { itens) }\end{array}$ & $1.976,5$ & 550 & 3,59 & 0,81 & 0,82 & 0,082 \\
\hline $\begin{array}{c}\text { Modelo } 4 \\
\text { (Cinco dimensões }-25 \\
\text { itens) }\end{array}$ & 837,3 & 265 & 3,16 & 0,88 & 0,90 & 0,075 \\
\hline $\begin{array}{c}\text { Modelo } 5 \\
\text { (Cinco dimensões }-25 \\
\text { itens ajustados) }\end{array}$ & 650,4 & 262 & 2,48 & 0,92 & 0,93 & 0,062 \\
\hline
\end{tabular}

Nota. Todos os valores de qui-quadrado foram significativos a $p<0,01$; TLI $=$ Tucker-Lewis Index; CFI = Comparative Fit Index, RMSEA = Root Mean Square Error of Approximation; $g l=$ grau de liberdade.

Desse modo, o modelo final do processo de adaptação Inventário de Estressores no Trabalho em Oncologia resultou em um instrumento com cinco dimensões e 25 itens no total, com indicadores psicométricos favoráveis na AFE e na AFC. A análise de correlações bivariadas entre as dimensões (correlações de Pearson) indicou relações consideradas de magnitude fraca ou moderada, de acordo com a classificação de Miles e Shevlin (2001). As de magnitude moderada foram quatro e ocorreram entre as seguintes dimensões: (i) carga de trabalho e sofrimento dos pacientes $(r=0,33$; $p<0,01)$; (ii) carga de trabalho e estresse com colegas de trabalho $(r=0,36 ; p<0,01)$; (iii) lidar com a morte e processo da morte e lidar com requisitos dos pacientes e familiares ( $r=-0,44 ; p<0,01)$; e (iv) lidar com a morte e processo da morte e sofrimento dos pacientes $(r=0,36$; $p<0,01)$. A Tabela 5 apresenta os valores das correlações bivariadas entre as dimensões.
Tabela 5

Coeficientes das correlações bivariadas entre as dimensões do Inventário de Estressores do Trabalho em Oncologia

\begin{tabular}{cccccccc}
\hline Dimensões & $M$ & $D P$ & 1 & 2 & 3 & 4 & 5 \\
\hline $\begin{array}{c}\text { (1) Carga de trabalho } \\
\text { (2) Lidar com a morte e }\end{array}$ & 3,5 & 1,5 & - & 0,24 & 0,33 & 0,36 & $-0,22$ \\
o processo da morte & 3,3 & 1,2 & & - & 0,36 & 0,24 & $-0,44$ \\
(3) Sofrimento dos & 4,0 & 1,0 & & - & 0,29 & $-0,24$ \\
$\quad$ pacientes & & & & & & - & $-0,19$ \\
(4) Estresse com cole- \\
$\quad$ gas de trabalho
\end{tabular}

Uma vez concluída a AFC, foi realizada a AFCMG. A Tabela 6 apresenta os resultados da série de AFC realizada com os dados do Inventário de Estressores no Trabalho em Oncologia. De maneira preliminar, foram conduzidas análises separadas para as bases de dados de enfermeiros e de outras categorias profissionais da área da saúde, que compreende médicos, assistentes sociais, psicólogos, nutricionistas e fisioterapeutas. Os conjuntos de dados confirmaram que a solução de cinco fatores do Inventário de Estressores no Trabalho em Oncologia apresentou bom ajuste tanto na base de dados de enfermeiros (Tabela 6, Modelo 1) quanto na de outras categorias profissionais da área da saúde (Tabela 6, Modelo 2). Assim, o Modelo 1 e o Modelo 2, que configuraram uma solução de cinco fatores do Inventário de Estressores no Trabalho em Oncologia, foram tomados como modelos de linha de base para a sequência de AFCMG, por meio das quais a equivalência de medição foi testada. Tabela 6

Modelos resultantes da análise de invariância do Inventário de Estressores do Trabalbo em Oncologia para enfermeiros e outros profissionais da saúde

\begin{tabular}{|c|c|c|c|c|c|c|}
\hline Modelos & $\chi^{2}$ & $g l$ & $\begin{array}{c}\chi^{2 /} \\
g l\end{array}$ & TLI & CFI & RMSEA \\
\hline $\begin{array}{c}\text { Modelo } 1 \\
\text { (Cinco fatores }- \text { Enfer- } \\
\text { meiros) }\end{array}$ & 520,1 & 262 & 1,99 & 0,89 & 0,90 & 0,079 \\
\hline $\begin{array}{c}\text { Modelo } 2 \\
\text { (Cinco fatores - Outros } \\
\text { profissionais da saúde) }\end{array}$ & 512,6 & 262 & 1,96 & 0,91 & 0,92 & 0,065 \\
\hline $\begin{array}{c}\text { Modelo } 3 \\
\text { (Equivalência configural) }\end{array}$ & $1.032,8$ & 524 & 1,97 & 0,90 & 0,91 & 0,050 \\
\hline $\begin{array}{c}\text { Modelo } 4 \\
\text { (Equivalência métrica) }\end{array}$ & $1.058,4$ & 544 & 1,95 & 0,90 & 0,91 & 0,050 \\
\hline $\begin{array}{c}\text { Modelo } 5 \\
\text { (Equivalência escalar) }\end{array}$ & $1.074,2$ & 559 & 1,92 & 0,90 & 0,91 & 0,049 \\
\hline $\begin{array}{c}\text { Modelo } 6 \\
\text { (Equivalência residual) }\end{array}$ & $1.126,8$ & 587 & 1,92 & 0,90 & 0,91 & 0,049 \\
\hline
\end{tabular}

Nota. TLI $=$ Tucker -Lewis Index , CFI = Comparative Fit Index; RMSEA = Root Mean Square Error of Approximation; $g l=$ grau de liberdade.

A primeira AFCMG testou um modelo de equivalência configural (Tabela 6, Modelo 3) avaliando simultaneamente o ajuste do Modelo 1 e do Modelo 2. Os índices de ajuste $\left(\chi^{2} / \mathrm{gl}=\right.$ 1,97; $\mathrm{CFI}=0,99 ;$ TLI $=0,98 ;$ RMSEA $=0,042)$ indicavam um bom ajuste para esse modelo, suportando uma solução equivalente de cinco fatores do Inventário de Estressores no Trabalho em Oncologia nos conjuntos de dados de enfermeiros e de outros profissionais da saúde, com manutenção de todos os itens e dimensões para os dois grupos. O Modelo 4 (Tabela 6) foi testado para equivalência métrica e não houve diferença entre o CFI superior a 0,01 , o que confirma a invariância das cargas fatoriais.

Aplicando a mesma lógica, o Modelo 5 (Tabela 6) testou a invariância escalar e obteve os índices de ajuste também satisfatórios 
e com diferença de CFI inferior a 0,01, confirmando, portanto, uma equivalência das covariâncias. Por fim, o Modelo 6 (Tabela 6), testou a invariância residual, cujos índices de ajuste foram também satisfatórios e manutenção no valor do CFI, indicando que há equivalência nos resíduos da medida para enfermeiros e outros profissionais. Assim, confirmou-se uma invariância da medida, que indica equivalência configural, métrica, escalar e residual.

Esses resultados suportam, portanto, a aplicação da medida para outros profissionais da saúde além dos enfermeiros, razão pela qual o nome do instrumento foi modificado para Inventário de Estressores no Trabalho em Oncologia. A versão final do inventário após adaptação à realidade brasileira é apresentada na Tabela 7 .

Tabela 7

Modelos resultantes da análise de invariância do Inventário de Estressores do Trabalbo em Oncologia para enfermeiros e outros profissionais da saúde

\begin{tabular}{|c|c|c|c|}
\hline \multirow[t]{2}{*}{ Fatores } & \multicolumn{2}{|r|}{ Itens } & $\begin{array}{l}\text { Carga } \\
\text { fato- }\end{array}$ \\
\hline & 1 & Trabalho excessivo. & 0,82 \\
\hline \multirow{6}{*}{$\begin{array}{l}\text { Fator } 1 \\
\text { Carga de } \\
\text { trabalho } \\
7 \text { itens } \\
\alpha=0,90\end{array}$} & 2 & Ter muitos pacientes. & 0,63 \\
\hline & 3 & Estar envolvido com muitas tarefas diferentes. & 0,74 \\
\hline & 4 & Pessoal insuficiente na equipe de apoio. & 0,65 \\
\hline & 5 & Falta de tempo. & 0,86 \\
\hline & 6 & Ter que trabalhar rapidamente. & 0,72 \\
\hline & 7 & Trabalho físico excessivo. & 0,63 \\
\hline \multirow{5}{*}{$\begin{array}{l}\text { Fator } 2 \\
\text { Lidar com } \\
\text { a morte e o } \\
\text { processo da } \\
\text { morte } \\
5 \text { itens } \\
\alpha=0,89\end{array}$} & 8 & $\begin{array}{l}\text { Morte de pacientes de quem nos aproxima- } \\
\text { mos. }\end{array}$ & $-0,69$ \\
\hline & 9 & Comunicar notícias ruins. & $-0,52$ \\
\hline & 10 & $\begin{array}{l}\text { Morte de pacientes jovens, de mães jovens ou } \\
\text { de crianças. }\end{array}$ & $-0,85$ \\
\hline & 11 & Presenciar momento da morte do paciente. & $-0,75$ \\
\hline & 12 & Pacientes jovens. & $-0,82$ \\
\hline \multirow{4}{*}{$\begin{array}{l}\text { Fator } 3 \\
\text { Sofrimento } \\
\text { dos pacientes } \\
4 \text { itens } \\
\alpha=0,87\end{array}$} & 13 & $\begin{array}{l}\text { Acompanhar a dor física e o sofrimento em } \\
\text { pacientes. }\end{array}$ & 0,78 \\
\hline & 14 & $\begin{array}{l}\text { Perceber o sofrimento emocional dos pacien- } \\
\text { tes. }\end{array}$ & 0,89 \\
\hline & 15 & Deterioração física dos pacientes. & 0,79 \\
\hline & 16 & Ausência de esperança terapêutica. & 0,49 \\
\hline \multirow{5}{*}{$\begin{array}{l}\text { Fator } 4 \\
\text { Estresse com } \\
\text { colegas de } \\
\text { trabalho } \\
5 \text { itens } \\
\alpha=0,85\end{array}$} & 17 & $\begin{array}{l}\text { Dificuldade de escuta por parte dos superiores } \\
\text { hierárquicos. }\end{array}$ & 0,61 \\
\hline & 18 & $\begin{array}{l}\text { Falta de reconhecimento pelo trabalho bem } \\
\text { feito. }\end{array}$ & 0,54 \\
\hline & 19 & Ter conflitos com colegas de trabalho. & 0,73 \\
\hline & 20 & Lidar com colegas desagradáveis. & 0,79 \\
\hline & 21 & $\begin{array}{l}\text { Comunicação deficiente entre colegas de } \\
\text { trabalho. }\end{array}$ & 0,75 \\
\hline \multirow{4}{*}{$\begin{array}{l}\text { Fator } 5 \\
\text { Lidar com } \\
\text { requisitos dos } \\
\text { pacientes e } \\
\text { familiares } \\
4 \text { itens } \\
\alpha=0,88\end{array}$} & 22 & Lidar com pacientes difíceis/exigentes. & 0,87 \\
\hline & 23 & $\begin{array}{l}\text { Lidar com familiares de pacientes difíceis/ } \\
\text { exigentes. }\end{array}$ & 0,88 \\
\hline & 24 & $\begin{array}{l}\text { Lidar com pacientes e/ou familiares hostis ou } \\
\text { violentos. }\end{array}$ & 0,81 \\
\hline & 25 & $\begin{array}{l}\text { Falta de cooperação de familiares com o } \\
\text { paciente. }\end{array}$ & 0,82 \\
\hline
\end{tabular}

\section{Discussão}

Este estudo teve por objetivo realizar a adaptação do Inventário de Estressores no Trabalho em Oncologia, desenvolvido por Borteyrou et al. (2013), para o Brasil, bem como realizar os testes iniciais de validade psicométrica. Entre os testes iniciais de validade, foi incluída a análise de invariância da medida para outras categorias profissionais da área da oncologia (assistentes sociais, fisioterapeutas, médicos, nutricionistas e psicólogos). Como condição para realização dessa análise, os dados amostrais foram apresentados de forma subdividida entre enfermeiros e demais categorias profissionais que atuam na área da oncologia. Foram também realizados testes $t$ que indicaram não haver nenhuma diferença significativa entre os dois grupos em nenhuma das variáveis de caracterização da amostra (idade, tempo de trabalho, tempo de trabalho na categoria profissional, tempo de trabalho na oncologia, número de especializações, carga horária semanal e quantidade de empregos).

O inventário original (Borteyrou et al., 2013) contempla cinco dimensões que são apontadas em diversos estudos sobre estressores no trabalho na área da saúde (Bandeira, 2017; Bandeira \& Oliveira, 2010; Bonneterre et al., 2011; Gray-Toft \& Anderson, 1981; Ratochinski et al., 2016; Sousa \& Araújo, 2015): carga de trabalho; lidar com a morte e o processo da morte; sofrimento dos pacientes; estresse com colegas de trabalho; e lidar com requisitos dos pacientes e familiares. $\mathrm{O}$ instrumento tem como vantagem ter sido desenvolvido especificamente para a área da saúde em oncologia, que possui peculiaridades em relação a outras especialidades (Onan et al., 2015; N. A. R. Santos et al., 2017; Silva, 2009).

Os resultados das análises com a amostra brasileira confirmaram a estrutura de cinco fatores do instrumento de Borteyrou et al. (2013), apesar da redução do número de itens. Inicialmente, nove itens da escala não apresentaram bom ajuste, sendo sete da dimensão "carga de trabalho" e dois da dimensão "lidar com a morte e o processo da morte". No caso da dimensão "carga de trabalho", os itens que não permaneceram na versão final da escala dizem respeito mais a uma carga emocional do trabalho do que propriamente ao excesso de trabalho, como, por exemplo, o sentimento de incapacidade de cuidar de pacientes, a tomada de decisão solitária, os conflitos entre o trabalho e a família e o medo de cometer erros. Nesse sentido, é possível que, para a amostra brasileira, tais itens não sejam percebidos como carga de trabalho. Tais resultados estão em consonância com os estudos de Andela et. al. (2016) e de Bandeira (2017), que discutem a questão da carga de trabalho para os profissionais da saúde e não consideram, de forma direta, a carga emocional do trabalho.

No caso da dimensão "lidar com a morte e o processo da morte", não saber o que fazer ou ter dúvida sobre o que dizer ao paciente são aspectos que nem sempre estão relacionados com a morte propriamente dita, apesar de ser difícil a comunicação de notícias ruins a pacientes e familiares (A. F. Santos \& Santos, 2015). O mesmo pode ser dito dos itens "ter que lidar com pacientes que você conhece"; "pacientes que me remetem a refletir sobre a minha própria existência"; e "pacientes que me remetem a pensar em pessoas próximas”. Esses itens não têm uma vinculação tão clara com a dimensão "lidar com a morte e o processo da morte", e possivelmente por isso não permaneceram na amostra brasileira.

Os itens "cuidar de doentes terminais" e "nenhuma recompensa para o desenvolvimento e o avanço da carreira" carregaram em mais de um fator, possivelmente porque tratam de aspectos gerais do trabalho em oncologia (Kitze \& Rodrigues, 2008; A. F. Santos \& Santos, 2015). Nesse sentido, o fato de não haver um fator para o trabalho oncológico como um todo pode ser uma possível explicação para a queda de alguns itens da medida.

Entretanto, mesmo considerando a possibilidade de haver itens gerais que atuem como estressores no trabalho em oncologia, a AFC indicou de forma clara que um modelo de fator geral não apresenta bom ajuste. Da mesma forma, também não se obteve um ajuste favorável do modelo sem correlações entre as dimensões. Nesse sentido, as correlações de magnitude fraca ou moderada entre as dimensões do inventário (Miles \& Shevlin, 2001) indicam que os cinco fatores da escala estão claramente definidos, confirmando o modelo original de cinco fatores correlacionados de Borteyrou et al. (2013). Além disso, os índices de consistência interna de to- 
das as dimensões foram muito bons, variando de 0,85 a 0,90 , e três deles estavam acima dos valores obtidos no inventário original.

Assim, de modo geral, os resultados indicaram que a versão brasileira do inventário apresentou dimensões consistentes, resultando em uma medida com possibilidade de aplicação a diferentes categorias profissionais que atuam em oncologia. As mudanças encontradas nos itens em termos de carregarem em outra dimensão, contudo, indicam para a necessidade de novas investigações, tendo em vista a comparação com o modelo original de Borteyrou et al. (2013).

O fato de o inventário ser invariante para enfermeiros e não enfermeiros amplia as possibilidades de uso da medida, no sentido de identificar e mensurar os fatores estressores no trabalho em oncologia de diferentes categorias ocupacionais. Tal resultado reveste-se de maior relevância na medida em que a literatura da área aponta para um predomínio de atuação em equipes multidisciplinares na área oncológica (Taplin et al., 2015). Além disso, o uso futuro desse instrumento também permitirá comparar as diferenças e similitudes nos fatores estressores das categorias, identificando as peculiaridades relativas a cada grupo profissional que atua na área.

Com relação ao expressivo percentual de mulheres na pesquisa, é possível fazer uma associação com a atribuição das práticas de cuidado na saúde à figura feminina (Barros \& Mourão, 2018; Sousa \& Araújo, 2015). O nível de escolaridade elevado também chama atenção, e possivelmente está associado ao fato de a oncologia exigir atualização constante de conhecimentos e desenvolvimento profissional, sendo muito frequente a realização de especializações e cursos de pós-graduação, apesar de a média de tempo de trabalho na categoria profissional não ser muito elevada. Por fim, o predomínio da amostra na Região Sudeste $(85,9 \%)$ pode estar associado à quantidade elevada de pessoas e à concentração de instituições especializadas no tratamento do câncer nessa região.

$\mathrm{O}$ instrumento apresentado fornece evidências de validade que possibilitam recomendar a sua utilização em pesquisas futuras sobre estressores no trabalho de profissionais brasileiros que trabalham na assistência a pacientes oncológicos. Contudo, os resultados obtidos requerem novos estudos com a medida. Um contraponto ao resultado obtido refere-se ao fato de que alguns itens que não permaneceram no inventário estejam presentes na literatura da área como fatores estressores dos profissionais da área da saúde. Exemplos desses itens seriam o medo de tomar decisões sozinho e de cometer erros (Kitze \& Rodrigues, 2008; A. F. Santos \& Santos, 2015). Esses elementos são relevantes, sobretudo se for considerado que algumas situações vivenciadas na área da oncologia requerem decisões rápidas. Nesse sentido, recomendam-se estudos de aprofundamento, possivelmente por meio de metodologia qualitativa, a fim de identificar por qual razão tais itens não permaneceram no Inventário de Estressores no Trabalho em Oncologia.

A despeito da necessidade de novas investigações sobre a medida, a apresentação de uma primeira versão do Inventário de Estressores no Trabalho em Oncologia supre uma lacuna em estudos dessa natureza, já que não havia no Brasil instrumento específico destinado a mensurar os estressores no trabalho em oncologia para diferentes categorias profissionais da área da saúde. Assim, o instrumento adaptado tem potencial de contribuir com a identificação de estressores e, consequentemente, com a saúde dos trabalhadores da assistência em oncologia. Como implicação prática, espera-se que as instituições de saúde desenvolvam estratégias e políticas de gestão de pessoas que sejam mais eficazes com relação à prevenção da saúde do trabalhador.

Apesar de a pesquisa ter sido composta por participantes de todas as regiões do Brasil, foi utilizada uma amostra de conveniência, o que limita a generalização dos resultados obtidos. Além disso, a amostra utilizada para a AFE e a AFC foi a mesma, o que também pode ser considerada uma limitação do estudo. Ainda, a pesquisa ficou circunscrita às evidências iniciais de validade da medida e ao fato de a invariância ter sido testada para apenas cinco categorias profissionais. Por fim, também pode ser considerada uma limitação o fato de não ter sido incluída uma medida de estresse, o que impede a realização de análises que separem a amostra entre profissionais com níveis mais elevados ou mais baixos de estresse.

Estudos futuros podem aprofundar os achados atuais. Sugere-se, por exemplo, uma nova redação para os itens que foram retirados da escala, para confirmar se eles devem ou não permanecer no Inventário de Estressores no Trabalho em Oncologia. Também é recomendável que haja investigação da estabilidade temporal da medida e das evidências de validade convergente, concorrente e discriminante. Seriam úteis, ainda, estudos com outras categorias ocupacionais do segmento, tais como farmacêuticos, fonoaudiólogos, dentistas, terapeutas ocupacionais e técnicos de enfermagem, a fim de identificar como os estressores presentes no instrumento se manifestam nas demais profissões da saúde na oncologia, não abrangidas por este estudo.

\section{Referências}

Alves, M. G. M., Chor, D., Faerstein, E., Lopes, C. S., \& Werneck, G. L. (2004). Versão resumida da Job Stress Scale: Adaptação para o português. Revista de Saúde Pública, 38(2), 164-171. https://doi.org/10.1590/S003489102004000200003

Andela, M., Truchot, D., \& Van der Doef, M. (2016). Job stressors and burnout in hospitals: The mediating role of emotional dissonance. International Journal of Stress Management, 23(3), 298-317. https://doi.org/10.1037/str0000013

Andolhe, R., Barbosa, R. L., Oliveira, E. M., Costa, A. L. S., \& Padilha, K. G. (2015). Estresse, coping e burnout da equipe de enfermagem de unidades de terapia intensiva: Fatores associados. Revista Escola de Enfermagem USP, 49(Esp.), 58-64. https://doi.org/10.1590/S0080-623420150000700009

Apostolico, M. R., \& Egry, E. Y. (2013). Uso da internet na coleta de dados primários na pesquisa em Enfermagem. Revista Brasileira de Enfermagem 66(6), 949-955. https://doi.org/10.1590/S0034-71672013000600021

Balayssac, D., Pereira, B., Virot, J., Collin. A., Alapini, D., Cuny, D., ... Vennat, B. (2017). Burnout, associated comorbidities and coping strategies in French community pharmacies - BOP study: A nationwide cross-sectional study. PLoS ONE, 12(8), 1-15. https://doi.org/10.1371/journal.pone.0182956

Bandeira, M. A. D. (2017). Estresse ocupacional em médicos: uma revisão bibliográfica. Revista Amazônia Science \& Health, 2, 25-32. https://doi. org/10.18606/2318-1419/amazonia.sci.health.v5n2p25-32

Bandeira, M. A. D., \& Oliveira, A. L. (2010). O estresse em profissionais da enfermagem: análise bibliográfica sobre a temática. Anais do X Encontro Latino Americano de Pós-graduação da UNIVAP, São José dos Campos, SP, Brasil. Recuperado de http://www.inicepg.univap.br/cd/INIC 2010/anais/ arquivos/0735 0950 01.pdf

Barros, S. C. V., \& Mourão, L. (2018). Panorama da participação feminina na educação superior, no mercado de trabalho e na sociedade. Psicologia \& Sociedade, 30, 2-11. https://doi.org/10.1590/1807-0310/2018v30174090

Bianchi, E. R. F. (2009), Escala Bianchi de stress. Revista Escola Enfermagem USP (Esp), 1055-1062. Recuperado de http://www.scielo.br/pdf/reeusp/ v43nspe/a09v43ns.pdf

Bonneterre, V., Ehlinger, V., Balducci, F., Caroly, S., Jolivet, A., Sobaszek, A., ... Lang, T. (2011). Validation of an instrument for measuring psychosocial and organizational work constraints detrimental to health among hospital workers: The NWI-EO questionnaire. International Journal of Nursing Studies 48(5), 557-567. https://doi.org/10.1016/i.ijnurstu.2010.09.006

Borsa, J. C., Damásio, B. F., \& Bandeira, D. R. (2012). Adaptação e validação de instrumentos psicológicos entre culturas: Algumas considerações. Paidéia, 22(53), 423-432. Recuperado de http://www.scielo.br/scielo. php? script $=$ sci arttext\&pid $=$ S0103-863X2012000300014

Borteyrou, X., Truchot, D., \& Rascle, N. (2013). Development and validation of the Work Stressor Inventory for Nurses in Oncology: Preliminary findings. Journal of Advanced Nursing. 70(2), 443-53. https://doi.org/10.1111/ jan. 12231

Brown, T. A. (2006). Confirmatory factor analysis for applied research. Nova York: The Guilford Press.

Bruschini, M., Carli, A., \& Franco, B. (2018). Burnout and work-related stress in Italian rehabilitation professionals: A comparison of physiotherapists, speech therapists and occupational therapists. Work, 59(1), 121-129. https://doi.org/10.3233/WOR-172657

Damásio, B. F. (2012). Uso da análise fatorial exploratória em psicologia. Avaliação Psicológica, 11(2), 213-228. Recuperado de http://pepsic.bvsalud.org/pdf/ avp/v11n2/v11n2a07.pdf 
Damásio, B. F. (2013). Contribuições da Análise Fatorial Confirmatória Multigrupo (AFCMG) na avaliação de invariância de instrumentos psicométricos. Psico-USF, 18(2), 211-220. https://doi.org/10.1590/S141382712013000200005

Gray-Toft, P., \& Anderson, J. G. (1981). Stress among hospital nursing staff: Its cause and effects. Social Sci Med, 15, 639-47. https://doi.org/10.1016/02717123(81)90087-0

Hair, J. F., Black, W. C., Babin, B. J., Anderson, R. E., \& Tathan, R. L. (2009). Análise Multivariada de Dados. Porto Alegre: Bookman.

Kitze, S., \& Rodrigues, A. B. (2008). Burnout em oncologia: Um estudo com profissionais de enfermagem. Einstein, 6(2), 128-133. Recuperado de http:// apps.einstein.br/revista/arquivos/PDF/591-Einstein $\% 20 \mathrm{v} 6 \mathrm{n} 2 \% 20 \mathrm{p} 128-33$. pdf

Lipp, M. E. N. (2000). Manual do Inventário de Sintomas de Stress para Adultos de Lipp (ISSL). São Paulo: Casa do Psicólogo.

Maturana, A. P. P. M., \& Valle, T. G. M. (2014). Estratégias de enfrentamento e situações estressoras de profissionais do ambiente hospitalar. Psicologia Hospitalar, 12(2), 2-23. Recuperado de http://pepsic.bvsalud.org/scielo. php? script $=$ sci arttext\&pid $=$ S1677-74092014000200002

Miles, J., \& Shevlin, M. (2001). Applying regression \& correlation. A guide for students and researchs. Londres: SAGE publications.

Oliveira, A. E. G., \& Cury, V. E. (2016). Cuidar em oncologia: uma experiência para além do sofrimento. Memorandum, 31, 237-258. Recuperado de https:// pesquisa.bvsalud.org/portal/resource/pt/biblio-914660

Onan, N., Barlas, G. Ü., Karaca, S., Yildirim, N. K., Taskiran, Ö., e Sümeli, F. (2015). The relations between perceived stress, communication skills and psychological symptoms in oncology nurses. Journal of Marmara University Institute of Health Sciences, 5(3). https://doi.org/0.5455/ musbed.20150602021515

Paschoal, T., \& Tamayo, A. (2004). Validação da escala de estresse no trabalho. Estudos de Psicologia, 9(1), 45-52. https://doi.org/ 10.1590/S1413294X2004000100006

Ratochinski, C. M. W., Powlowytsch, P. W. M., Grzelczak, M. T., Souza, W. C., \& Mascarenhas, L. P. G. (2016). O estresse em profissionais de enfermagem: Uma revisão sistemática. Revista Brasileira de Ciências da Saúde, 20(4), 341-346. https://doi.org/10.4034/RBCS.2016.20.04.12

Revicki, D. A., May, H. J., \& Whitley, T. W. (1991). Reliability and validity of the work-related strain inventory among health professionals. Behavioral Medicine, 17(3), 111-120. Recuperado de http://www.tandfonline.com/doi/abs/10.10 $\underline{80 / 08964289.1991 .9937554}$

Ribeiro, R. P., Marziale, M, H. P., Martins, J. T., Galdino, M. J. Q., \& Ribeiro, P. H. V. (2018). Estresse ocupacional entre trabalhadores de saúde de um hospital universitário. Revista Gaúcha de Enfermagem, 39. https://doi. org/10.1590/1983-1447.2018.65127

Santos, A. F., \& Santos, M. A. (2015). Estresse e burnout no trabalho em oncologia pediátrica: Revisão integrativa da literatura. Psicologia: ciência e profissão, 35(2), 437-456. https://doi.org/10.1590/1982-370300462014

Santos, N. A. R., Santos, J., Silva. V. R., \& Passos, J. P. (2017). Estresse ocupacional na assistência de cuidados paliativos em oncologia. Cogitare Enfermagem, 22(4):e50686. https://doi.org/10.5380/ce.v22i4.50686

Sanzovo, C. E., \& Coelho, M. E. C. (2007). Estressores e estratégias de coping em uma amostra de psicólogos clínicos. Estudos de Psicologia, 24(2), 227-238. Recuperado de http://www.scielo.br/pdf/estpsi/v24n2/v24n2a09.pdf

Selye, H. (1956). The stress of life. New York: McGraw-Hill Book Company.

Sena, A. F. J., Lemes, A. G., Nascimento, V. F., \& Roch, E. M. (2015). Estresse e ansiedade em trabalhadores de enfermagem no âmbito hospitalar. Journal of Nursing and Health, 5(1), 27-37. https://doi.org/10.15210/JONAH. V5I1.5089

Silva, A.M., Rodrigues, C.D.S., Silva, S.M.R., \& Witt, R.R. (2009). Utilização da técnica Delphi on-line para investigação de competências: relato de experiência. Revista Gaúcha de Enfermagem, 30(2), 348-351. Recuperado de https://seer.ufrgs.br/RevistaGauchadeEnfermagem/article/ view $/ 7274 / 6695$

Silva, L. C. (2009). O sofrimento psicológico dos profissionais de saúde na atenção ao paciente de câncer. Psicologia para América Latina, 16. Recuperado de http://pepsic.bvsalud.org/scielo.php? script $=$ sci arttext\&pid=S1870$350 \mathrm{X} 2009000100007 \& \operatorname{lng}=\mathrm{pt} \& t \operatorname{lng}=\mathrm{pt}$

Sousa, V. F. S., \& Araújo, C. C. F. (2015). Estresse ocupacional e resiliência entre profissionais de saúde. Psicologia Ciência e Profissão, 24(3), 900-915. https:// doi.org/10.1590/1982-370300452014

Taplin, S. H., Weaver, S., Salas, E., Chollette, V., Edwards, H. M. Bruinooge, S. S., \& Kosty, M. P. (2015). Reviewing cancer care team effectiveness. Journal of Oncology Practice, 11(3), 239-246. https://doi.org/10.1200/JOP.2014.003350

Wolfgang, A. P. (1988). The health professions stress inventory. Psychological Reports, 62, 220-222. https://doi.org/10.2466/pr0.1988.62.1.220 